Table 1. AfTershocks of The Yellowstone Park Earthquake OF AUGUST 18 (ALL DURING AUGUST)

\begin{tabular}{|c|c|c|c|c|c|c|}
\hline \multicolumn{4}{|c|}{$\begin{array}{l}\text { Initial day and time } \\
\text { (G.M.T.) }\end{array}$} & \multicolumn{2}{|c|}{ Epicentre } & $\begin{array}{l}\text { Magnitude } \\
\text { Richter } \\
\text { Scale }\end{array}$ \\
\hline Day & Hour & Minute & Second & (on.) & $\begin{array}{l}\text { Long. } \\
\left({ }^{\circ} \text { W. }\right)\end{array}$ & M \\
\hline 18 & 07 & 54 & 32 & 45 & 111 & - \\
\hline 18 & 15 & 26 & 06 & $44 \frac{1}{2}$ & 111 & $6 \frac{1}{2}$ \\
\hline 19 & 04 & 04 & 03 & $45^{\circ}$ & $111_{\frac{1}{2}}^{\frac{1}{2}}$ & $6^{2}$ \\
\hline 19 & 19 & 06 & 29 & 45 & $111 \cdot 4$ & - \\
\hline 19 & 19 & 43 & $45 \cdot 7$ & 45 & $110 \frac{1}{2}$ & - \\
\hline 19 & 21 & 45 & 57 & 45 & $111 \frac{1}{2}$ & - \\
\hline 20 & 10 & 59 & 11 & 45 & 111 & \\
\hline 20 & 19 & 11 & 27 & 45 & 111 & - \\
\hline
\end{tabular}

From the first of these epicentres earthquakes on June 27, 1925, reached intensity 10 on the RossiForel Scale and caused greatest damage at Man- hattan, Logan, Three Forks and Lombard. From the second location shocks in October and November, 1935, attained maximum intensity 9 on the RossiForel Scale. However, minor shocks of intensity 4-5 (R.F. Scale) from an epicentre in Yellowstone National Park, Wyoming $\left(44^{\circ} \mathrm{N} ., 111^{\circ} \mathrm{W}\right.$.), oceurred at various times from August 24 to December 22, 1930. In 1947 (November 23 ) at $09 \mathrm{~h} .46 \mathrm{~m}$. 05s. G.M.T. a shallow focus earthquake from an epicentre $44 \frac{3}{4}^{\circ} \mathrm{N} ., 111^{\frac{3}{4}} \mathrm{~W}$. reached a magnitude $6 \frac{1}{4}$ on the Richter Scale. Earthquakes are always liable to recur at or near old epicentres.

Aftershocks of the earthquake of August 1959 so far listed by the United States Coast and Geodetic Survey are given in Table I, although smaller shocks are said to have occurred at intermediate times.

E. Tillotson

\title{
A THEORY OF AGEING
}

$\mathrm{T}$ THE theory of ageing put forward by Szilard refers explicitly to mammals. It is the purpose of the present communication to point out that this theory cannot explain ageing in Drosophila, since it is inconsistent with two experimental observations. This of course does not prove that it cannot explain ageing in mammals; but reasons will be given for doubting that it does so.

Szilard postulates the random occurrence of 'hits', each hit rendering ineffective the genes of a whole chromosome, or perhaps of a large segment of a chromosome. A cell becomes ineffective either when two homologous chromosomes have each suffered a hit, or when one of a pair of homologues has suffered a hit, and the other carries an inherited 'fault'. By a fault is meant a recessive gene which in homozygous condition renders the cell inviable, or incapable of performing a necessary function in the adult organism. Death occurs when some predetermined fraction of the cells initially present is in this way rendered ineffective; Szilard suggests that this fraction is of the order of $2 / 3$ to $11 / 12$.

It is a direct consequence of this theory that, in the author's words: "The main reason why some adults live shorter lives and others live longer is the difference in the number of faults they have inherited". This is the first consequence of the theory which is contradicted by observations on Drosophila. In so far as differences in adult longevity are genetically determined, by far the largest differences are those between inbred and outbred individuals ${ }^{2,3}$. $F_{1}$ hybrids between inbred lines live for longer than do the parental lines (sometimes for twice as long). Outbred and genetically variable wild populations have approximately the same expectation of life as do $F_{1}$ hybrids. Now inbreeding increases the proportion of loci at which individuals are homozygous. An individual which survives for an appreciable time as an adult cannot, by definition, be homozygous for a fault. Therefore inbred individuals which survive to become adults, and which do not die immediately after emergence, are not homozygous for faults at any loci, and would be expected to be heterozygous for faults at fewer loci than are members of outbred wild populations. If two inbred lines are crossed, the $F_{1}$ hybrids would be expected to carry a load of faults intermediate between the loads carried by the parental lines. Thus according to Szilard's theory, inbred lines should have a higher expectation of life than wild populations, and $F_{1}$ hybrids between inbred lines should be intermediate between their parents. Neither of these predictions is in fact true.

Further, since males have only a single $X$ chromosome, any hit on that chromosome in a male would render the cell inviable, whereas in a female not heterozygous for a sex-linked fault both $X$ chromosomes must be hit before a cell becomes inviable. Therefore females should live longer than males. This again is not the case in D. subobscura. In some strains females do live longer than males, but in other strains, both inbred and outbred, the reverse is true. This point is particularly telling since in Drosophila the sex chromosomes account for about one-fifth of the total chromosome material.

The other group of facts which are inconsistent with the theory concern the rate of ageing at different temperatures". Female D. subobscura of a particular strain have an expectation of life of about 56 days at $20^{\circ} \mathrm{C}$. and of 18 days at $30.5^{\circ} \mathrm{C}$. The changes responsible for death at $30 \cdot 5^{\circ} \mathrm{C}$. are not repaired or reversed in individuals kept for a time at $20^{\circ} \mathrm{C}$. Consequently the changes responsible for death at both temperatures can properly be regarded as ageing processes. If these processes were, at each temperature, those postulated by Szilard, differing only in the rate at which hits occur, it follows that individuals kept for an appreciable time at $30.5^{\circ} \mathrm{C}$. should have, when returned to $20^{\circ} \mathrm{C}$., an expectation of life at that temperature lower than that of individuals of the same chronological age not previously exposed to $30 \cdot 5^{\circ} \mathrm{C}$. In fact, exposure to $30 \cdot 5^{\circ} \mathrm{C}$. for periods of the order of half the expectation of life at that temperature does not alter the further expectation of life at $20^{\circ} \mathrm{C}$. of males, and significantly increases that of females.

Hence, if, despite the genetic evidence to the contrary, we assume that ageing at $20^{\circ} \mathrm{C}$. is due to random hits on chromosomes, then ageing at $30.5^{\circ} \mathrm{C}$. cannot be explained by the same process proceeding at a higher rate. In other words, either at $20^{\circ} \mathrm{C}$. or at $30.5^{\circ} \mathrm{C}$. ageing must be due to a process different from that postulated by Szilard ; it is possible, and in my view likely, that such a process is not primarily responsible for ageing at either temperature.

It is perhaps unreasonable to criticize a theory intended to explain ageing in mammals by quoting 
observations on insects. Unfortunately the tempera. ture experiments cannot be repeated on a homiotherm. But there is some evidence ${ }^{5}$ in mice, as well as in Drosophila, that inbred individuals do not live as long as outbred ones. In addition to this purely observational point, there is one more general reason why Szilard's work has made a theory of ageing by somatic mutation less, and not more, promising than it had previously appeared to be. It is assumed that the 'target' is a whole chromosome; a 'hit' renders ineffective all the genes carried by that chromosome. This assumption is made because, as Szilard shows, if it were assumed that the target were an individual gene, it would be necessary also to assume that each individual carried a load of faults so high as to be inconsistent with the known fertility of consanguineous marriages. There are events, particularly mitotic errors and chromosome breakages, which would deprive cells of whole chromosomes or of large segments of chromosomes, but they do not seem likely to be common enough to be the main cause of ageing. Most biologists would be happier with a theory which assumed as the unit event a hit on a gene, using the word gene here to refer to a functional unit or cistron. Perhaps the most important thing Szilard has done is to show that such a theory, at least in its simplest form, would run into difficulties.

Department of Zoology,

\section{J. Maynard Smith}

\section{University College,} London, W.C.l.

${ }^{1}$ Szilard, L., Proc. U.S. Nat. Acad. Sei, 45, 30 (1959).

${ }^{2}$ Clarke, J. M., and Maynard Smith, J., J. Genet., 53, 172 (1955).

${ }^{3}$ Maynard Smith, J., J. Genet., 56, 227 (1959).

4 Maynard Smith, J., J. Exp. Biol., 35, 832 (1958)

${ }^{5}$ Mühlbock, O., CIBA Colloguia on Ageing, 3, 115 (1957).

Ale the observations quoted by Mr. Smith in his interesting communication relate to fruit flies and they fall into two classes: observations which we may expect to be able to duplicate in the case of mammals and those which we may not. Since I do not propose to discuss here whether the theory might or might not be extended to insects, I am primarily concerned with the former of the two classes.

Smith states that a genetically variable, 'wild', population of fruit flies has a substantially higher life expectancy than inbred, fairly or wholly homozygous, strains derived from it. He also states that the $F_{1}$ hybrid, obtained by crossing two different inbred strains, has a substantially higher life expectancy than the two inbr ad strains themselves. Smith holds that these findings are not compatible with the theory of ageing that I proposed.

It is probably true that the observations quoted above could be duplicated with mammals and I am quite prepared to accept this thesis for the sake of argument. As I shall presently show, however, my theory does not preclude that the homozygous inbred strains may have a substantially smaller life expectancy than the wild type strains. Further, the theory demands that the life expectancy of the $F$, hybrid be appreciably higher than that of the wild type strain, if the wild type strain carries a substantial number of faults. In order to see this, we may consider the following.

At present there is no evidence that a gene may be responsible for anything except for the production of a specific protein molecule which might be endowed with a specific enzymatic activity. In a wild popula- tion, a given gene may be present in the form of a variety of alleles and the corresponding enzymes may differ in their turnover number. For the purposes of discussion here, I shall call an allele 'weak' if the turnover number of the corresponding enzyme is small. If this turnover number is very small, the allele might be a recessive lethal. A completely homozygous strain is, of course, free of recessive lethals, but it may contain a number of 'weak' alleles.

Again, for the purposes of discussion here, I shall adopt a somewhat over-simplified pieture, and shall disregard the possibility that the enzyme-levels in the somatic cells may be determined to some extent by the regulatory mechanisms of the cell through enzyme induction or otherwise. On this over-sim. plified basis, we may then say that the somatic cells of an inbred strain, which is homozygous for a number of 'weak' alleles, are impoverished in the correspond. ing enzymes, so far as their biochemical activity is concerned.

My theory assumes that only a small fraction of the enzymes, less than one-fifth perhaps, is important for the functioning of the somatic cells of the adult, while practically all of the enzymes may be important for differentiation and morphogenesis during the embryonic life of the individual. Accordingly, we may then expect that an individual of the inbred strain (which is homozygous for a number of 'weak' alleles) may be maldeveloped, in the sense that it may have a much smaller reserve at birth than the wild type individual, with respect to a number of physiological functions. Thus it is conceivable that an individual belonging to an inbred strain may die at an age at which $f$, the 'surviving' fraction of its somatic cells, has fallen to, say, $f^{*}=\frac{1}{2 \cdot 72} \approx \frac{1}{e}$; whereas an individual belonging to the wild-type strain may die at an age at which $f$, the 'surviving' fraction of its somatic cells, has fallen to about $f^{*}=\frac{1}{7 \cdot 4} \approx \frac{1}{e^{2}}$.

We may compute for this case the most probable age at death, for man, from formula (14) given on p. 33 of my paper (loc. cit.), which reads :

$$
x_{r}+r=\sqrt{4 m \ln \frac{1}{f^{*}}+\ln \frac{1}{f^{*}}}
$$

where $x_{r}$ is the number of hits at death; $r$ is the number of the inherited faults ; $m=23$ is the number of chromosome pairs and $f^{*}$ is the surviving fraction. of the somatic cells at the age of death.

The most probable age at death, $t_{r}$, is given by : $t_{r}=6 \times x_{r}$ years.

For the inbred strain we obtain $t_{r}$, the most probable age at death, by writing : $r=0$ and $\ln \frac{1}{f^{*}} \approx 1$. We thus obtain $t_{r}=63 \cdot 6$ years.

For the wild type we obtain $t_{r}$, the most probable age at death, by writing : $r=2$ and $\ln \frac{1}{f^{*}} \approx 2$. We thus obtain $t_{r}=81.5$ years. The actual value for white females in the United States is : $t_{r}=80.5$ years.

For the $F_{1}$ hybrid we obtain $t_{r}$, the most probable age at death, by writing: $r=0$ and $\ln _{\frac{f *}{f^{*}}} \approx 2$. We thus obtain $t_{r}=93.5$ years. This is 12 years more than the value for the wild type.

It may thus be seen that a substantially shortened life expectancy of the homozygous, inbred strain, as 